\title{
EFFECT OF HEALTH BELIEFS MODEL BASED PROGRAM FOR PATIENTS UNDERGOING HAEMODIALYSIS ON THEIR QUALITY OF LIFE ${ }^{1}$ Mona Salah Mustafa, ${ }^{2}$ Kamilia Fouad, ${ }^{3}$ Wafaa Ismail Sherif \\ ${ }^{1}$ clinical instructor, nursing institute, Benha University, ${ }^{2}$ professor Medical - Surgical nursing, Faculty of nursing, Ainshames University, \\ ${ }^{3}$ Professor Medical - Surgical nursing, ,Faculty of nursing, Mansoura University E-mail of the corresponding author: monaabdellatif49@yahoo.com
}

Abstract:

Hemodialysis is a physically stressful procedure and most of the elderly patients will have fatigue. Fatigue is a common and debilitating symptom, affecting 42-89\% of endstage kidney disease patients. It is a complex, multidimensional, and multifactorial phenomenon with huge repercussions on functioning, quality of life and elderly patient outcomes. Aim: determine the relationship between fatigue and functional status of the elderly patients on hemodialysis. Method: A descriptive co-relational design was used. Setting: This study was carried out at the hemodialysis unit at New Mansoura General Hospital in Mansoura city affiliated to the Ministry of Health. Tools: Data was collected using 4 tools, Tool I : Structured interview questionnaire sheet, Tool II: Katz and Akpom scale , Tool III: Lawton and Brady scale, Tool IV: Multidimensional Fatigue Inventory Scale (MFI-20).Results: the study revealed that about half of the studied elderly $(51.8 \%)$ have high level of fatigue and there is a significant correlation between fatigue and the functional status of the elderly patients on hemodialysis. Conclusion \& recommendation: The frequency of fatigue is high among hemodialysis patients. Fatigue has an effect on the functional status of hemodialysis elderly patients. Development \& Implementation of Health educational programs for newly elders on hemodialysis about hemodialysis process and fatigue and its management.

Key words: Fatigue, Functional status, Elderly, Hemodialysis.

\section{Introduction:}

The health belief model is a psychological health behavior change model developed to explain and predict health-related behaviors, particularly in regard to the uptake of health services. The health belief model suggests that people's beliefs about health problems, perceived benefits of action and barriers to action, and self-efficacy explain engagement (or lack of engagement) in health-promoting behavior. A stimulus, or cue to action, must also be present in order to trigger the health-promoting behavior [1]. Components of health beliefs models are perceived severity Refers to subjective assessment of the severity of a problem of health and its potential consequences, perceived susceptibility refers to subjective assessment of risk of developing a health problem. The health belief model predicts that individuals who perceive that they are susceptible to a particular health problem will engage in behaviors to reduce their risk of developing the health problem, perceived benefits refer to an individual's assessment of the value or efficacy of engaging in a health-promoting behavior to decrease risk of disease, perceived barriers refer to an person's assessment of the obstacles to 
behavior change, a cue, or trigger, is necessary for prompting engagement in health-promoting behaviors, and selfefficacy refers to an individual's perception of his or her competence to successfully perform a behavior ${ }^{[2]}$. Health Belief Model (HBM) that considers behavior as a function of one's data and perspective, and in step with its elements it's designed supported the thought of inflicting awareness of a health threat in individuals to guide their behavior towards health. This model will increase patients' data perceived susceptibleness and severity regarding the sickness and considering the perceived edges and barriers and cues to action, lead the individual toward health-centered behavior. In step with this model, the individual adopts health-improving behaviors ${ }^{[3]}$. Quality of life (QOL) is the general well-being of individuals and societies. QOL has a wide range of contexts, including the fields of international development, healthcare, politics and employment. When we look at health related quality of life (HRQOL) we in impact examine QOL and its relationship with health. HRQoL is the psychological, physical, and social domains of health that square measure distinctive to every individual. The financial gain, freedom, and also the atmosphere are different valued aspects of life exist that aren't typically including "health. Every of those domains will be measured by the target assessments of health or functioning standing and also the subjective perceptions of health. It's been outlined as follows: "HRQoL is outlined because the price appointed to length of life as changed by impairments, purposeful states, perceptions, and social opportunities that are influenced by sickness, injury, policy, or treatment [4]. Some authors believe that the detection of systems of health beliefs help health professionals take a proper care plan, which covers various beliefs. Regarding the value of health beliefs, the authors argue that in order to strengthen preventive behaviors, besides being aware of the behaviors, the patient should believe that preventive behavior has maintained his/her health and protected him/her against disease consequences, hence encouraging them to show appropriate behaviors ${ }^{[5]}$ Nursing care in this context is to help patients deal with their situational derived needs. The goal of which, is to reduce disability and control dependency. The nurse role as information giver is a very important one. Patients on dialysis present a problem. Information must be given simply and patiently repeated. The nurse plays a critical role in providing information, support, understanding and therapeutic counseling to the patient and his family throughout the entire illness. The nursing care must be provided in order to avoid the complications of reducing renal function and the stresses and anxieties of dealing with a life threatening illness ${ }^{[6]}$.

\section{Significance of the study}

It has been observed over a period of five years' experience in renal dialysis unit that patients, with chronic renal failure and undergoing hemodilaysis got some physical, psychological and social problems, the patient must be learned and must be adapted with his illness. It is very important for the patient to know causes of his disease, risk factors and patients' selfcare. Chronic kidney disease is a worldwide public health problem and the prevalence of chronic renal failure during one year 2012 per million population in some countries was: Arabian Peninsula was 70-110, East Asia was 80-100, North Africa was 120-170, south America was 120-160, North America was 160-170, and in Egypt was 300. This report from World Health Organization in December 2013 [7]. This is in light of the findings 
documented by Lindberg (2010) ${ }^{[8]}$, Effective management of excessive fluid overload in haemodialysis patients is dependent on the recognition that the patient is the main manager. Frequent and repeated contacts with renal nurses can help these patients develop problemsolving skills, set goals, and understand their progress in managing multiple aspects of their disease. As well, Farrokhi (2013) ${ }^{[9]}$. demonstrate that nursing support is critical to help patients develop proficiency in performing certain skills and tasks. Individualization of the common educational approach by incorporating the patient's beliefs, behaviors, and emotional and physical feelings as well as culture, economic situation, ability and knowledge of the disease and its treatment supports selfmanagement. So the researcher pretends to conduct this study, to evaluate the effect of HB $M$ based program for promoting healthy behaviors among the patients undergoing $\mathrm{HD}$ on their QoL.

\section{Aims of study:}

The present study aimed to Investigate the effect of the health belief Model (HBM) based program on quality of life of haemodialysis patients.

\section{Research hypothesis}

To fulfill the aim of the study, the following research hypotheses was formulated: The health belief Model (HBM) based program will improve health related behavior, knowledge and quality of life for patients undergoing haemodialysis

\section{Subjects and Method: \\ Study Design:}

A quasi-experimental design was used in this study.

\section{Setting:}

The study was conducted in artificial kidney Unit of Benha University Hospital. Subjects:

A purposive sample of all adult patients, admitted through a period of 6 months, at previously mentioned above setting and diagnosed with chronic renal failure and undergoing haemodialysis, the actual number of patients under study was 147 drop out of a few number the sample ( 5 patients), and fulfilling the following criteria:

Inclusion criteria:

- Their age ranged between $20-60$ years old.

- Able to communicate.

Exclusion criteria:

- Mentally retarded.

- Unconscious patients.

- Cancer patients

- Congestive heart failure

- Chronic obstructive pulmonary disease

Tools:

1. Assessment form which consists of two parts:

a) Socio-demographic data

b) Knowledge assessment

2. Health behavior form for haemodailysis patients it was assessed healthy patients perceptions and attitudes toward disease and management.

3. Quality of life (QOL) scale was used to determine the level of QOL for dialysis patients.

4. Laboratory investigation

Health beliefs model based program it is a program for such group of patients tailored or designed for haemodialysis patients focusing on the healthy behaviors of improving their quality of life, knowledge, and laboratory investigation.

\section{Field work:}

To carry out the study, ethical approval was obtained from the Official letters were issued to hospital director and nursing director of Benha University Hospital from the faculty of nursing explaining the aim of the study to obtain permission for the collection of data. Data was collected 
in the following manner: the researcher visited the unit in morning, after-noon, and evening shift for three to five days/week. The aim of the study and component of the tools were explained to patients under study at the beginning collection of data. The researcher filled the data collection tools within 60-90 minutes each tool take about 20 minutes (sometimes filled into 2 days for the same patient). Only two to three patients were met every visit. Patient's socio-demographic characteristics and medical data, patients knowledge, health related behavior, quality of life, and laboratory investigation, were filled pre and after health beliefs model based program implementation. Implementation of health beliefs model based program is done in the following manner: Each patient was interviewed separately by the researcher within the patient's room. The sessions number is 15 sessions in keeping with patient's needs; every session lasted from 60-90 minutes. Every patient should be invited to return to the researcher whenever he/she wishes, for any reason through telephone contact. Implementation of health beliefs model based program lasted over period of 3 months. It was done for developing health beliefs for patients with renal failure. This was conducted through four phases: perceived threat, perceived benefits, implementation and evaluation.

\section{Validity and reliability:}

- The tools were revised for content validity to determine whether the tool covers the aim. The tools revised by (7) expertise in that field- validity Professor, assistant professor, and lecturer (Ain Shams University 2 professor and 1 assistant professor, El-Mansoura University 1 assistant professor and 1 lecturer, El-Menia University 1 assistant professor, and Benha University 1 lecturer ). Reliability of knowledge questionnaire was (0.78). Reliability of health behavior questionnaire to avoid infection was $(0.86)$, health behavior to avoid urinary tract infection was (0.79), health behavior about nutrition for haemodailysis was (0.83), health behavior to avoid renal failure complication was (0.79), health behavior to Skin care was (0.94), health behavior to fistula care was (0.92), health behavior for medication regimen was (0.83), health behavior to improve activity and body condition was (0.79), health behavior for follow up program was (0.84), health behavior to avoid stress was (0.81), health behavior for marriage relationship was (0.93), health behavior to improve Social relationship was (0.98), health behavior to improve Spiritual condition was (0.95), health behavior to improve Emotional condition was (0.86). Reliability of Quality of life (QOL) scale related physical condition was (0.86),reliability of Psychosocial condition was (0.94), reliability of social condition was $(0.87)$, reliability of spiritual condition was (0.79), and reliability of activity of daily living was (0.89). Tool reliability was done using cronbach's alpha test

\section{Pilot study:}

The pilot study was carried out $10 \%$ from the total sample in order to evaluate the feasibility and applicability of tools and to estimate the proper time required for answering the questions. The tool was modified based on the results of the pilot study and the opinion of experts.

\section{Ethical consideration:}

Before carry out of the study, moral approval was obtained from the Scientific Research moral Committee at faculty of nursing in Mansoura University. Additionally, oral consent was obtained from every participant. Patients were 
EFFECT OF HEALTH BELIEFS MODEL BASED PROGRAM etc...

assured that anonymity and confidentiality would be guaranteed and that they have the right to withdraw from the study at any time without giving any reason.

\section{Statistical design:}

Up on completion of data collection were organized, categorized, tabulated and statistically analyzed. Data analyzed by using the statistical Package for Social Science (SPSS) version 15, to evaluate the change in patients under the study (pre-and post health beliefs model based program implementation). Data were presented in tables and charts using numbers and percentages. The statistical analysis included percentage $(\%)$, mean, standard deviation (SD), range, Chi-square (X2), Ztest and Pearson coefficient ( $r$ ). The observed differences, and associations were considered statistically significant $P$ $<0.05$.

\section{Results:}

Table 1: Demonstrates the mean score of patients knowledge regarding general knowledge about renal failure pre-and post intervention, it was indicated that there was a highly statistical significant ( $\mathrm{P}$ $<0.001$ ).

Table (1): The mean score of patients knowledge regarding general knowledge about renal failure pre-and post-intervention Knowledge assessment ( $\mathrm{N}=142$ ).

\begin{tabular}{|c|c|c|c|c|}
\hline \multirow{2}{*}{ Item } & Pre-program & Post-program & Paired t & \multirow{2}{*}{ P value } \\
\cline { 2 - 3 } & Mean \pm SD & Mean \pm SD & -17.748 & $<0.001^{* *}$ \\
\hline Kidney function & $.7394 \pm .84786$ & $2.3944 \pm .69402$ & -16.755 & $<0.001^{* *}$ \\
\hline Risks for renal failure & $.8662 \pm .81848$ & $2.3521 \pm .68621$ & -4.810 & $<0.001^{* *}$ \\
\hline Causes of renal failure & $1.2606 \pm 2.86747$ & $2.4577 \pm .66974$ & -17.748 & $<0.001^{* *}$ \\
\hline Symptom of kidney failure & $.7887 \pm .84912$ & $2.4437 \pm .69979$ & -14.733 & $<0.001^{* *}$ \\
\hline $\begin{array}{c}\text { The treatment of chronic } \\
\text { renal failure }\end{array}$ & $.8592 \pm .93469$ & $2.3803 \pm .74121$ & -21.265 & $<0.001^{* *}$ \\
\hline Complication of renal failure & $.6761 \pm .67948$ & $2.3944 \pm .69402$ & -640 \\
\hline
\end{tabular}

Table 2: illustrates the mean score of patients knowledge regarding the care of renal failure pre-and post intervention, it was indicated that there was a highly statistical significant difference $(\mathrm{P}<0.001)$.

Table (2): The mean score of patients knowledge regarding the care of renal failure pre-and post-intervention ( $\mathrm{N}=142$ ).

\begin{tabular}{|c|c|c|c|c|}
\hline \multirow{2}{*}{ Item } & Pre-program & Post-program & \multirow{2}{*}{$\begin{array}{c}\text { Paired } t \\
\text { test }\end{array}$} & \multirow{2}{*}{$P$ value } \\
\hline & Mean \pm SD & Mean \pm SD & & \\
\hline Definition of hemodialysis & $.8592 \pm .85545$ & $2.2887 \pm .76799$ & -14.347 & $<0.001 * *$ \\
\hline $\begin{array}{l}\text { Precaution during } \\
\text { hemodialysis }\end{array}$ & $1.0000 \pm .94531$ & $2.2746 \pm .76394$ & -11.885 & $<0.001 * *$ \\
\hline Side effects of hemodialysis & $1.2606 \pm 1.18907$ & $2.4577 \pm .66974$ & -10.225 & $<0.001 * *$ \\
\hline $\begin{array}{l}\text { Nutritional intake of patients } \\
\text { with renal failure }\end{array}$ & $.8873 \pm .91558$ & $2.3944 \pm .69402$ & -15.917 & $<0.001 * *$ \\
\hline $\begin{array}{l}\text { Fluid intake of patients with } \\
\text { renal failure }\end{array}$ & $.8944 \pm .85641$ & $2.2324 \pm .75948$ & -13.601 & $<0.001 * *$ \\
\hline Skin care & $.5704 \pm .80246$ & $2.4718 \pm .70150$ & -19.909 & $<0.001 * *$ \\
\hline Fistula care & $.5141 \pm .79659$ & $2.4718 \pm .67049$ & -23.776 & $<0.001 * *$ \\
\hline
\end{tabular}




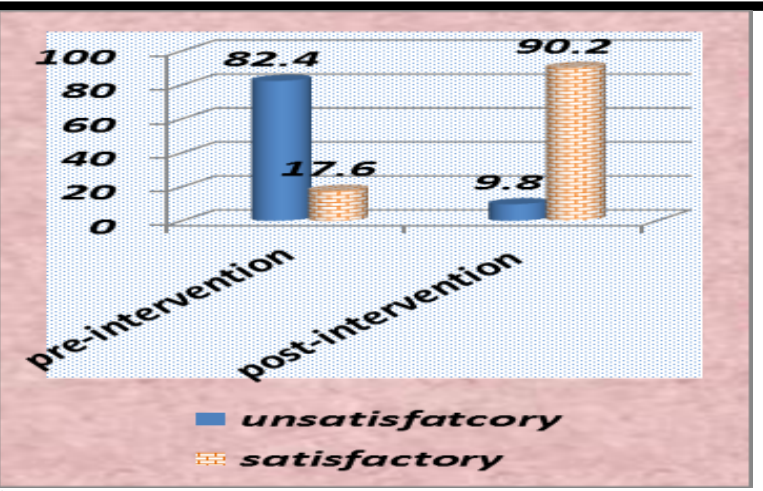

Figure (1): percentage distribution of total knowledge of studied patients

This figure illustrates the mean score of patients knowledge regarding the care of renal failure pre-and post-intervention, it was indicated that there was a highly statistical significant difference $(\mathrm{P}<0.001)$.

Table (3):Distribution of total score for healthy behaviors related main aspects among the studied patients pre and post intervention, it was showed that there was a highly statistical significant difference $(\mathrm{P}<0.001)$.

Table (3): Distribution of total score for healthy behaviors related main aspects among the studied patients pre and post intervention $(\mathrm{N}=142)$.

\begin{tabular}{|c|c|c|c|c|c|c|c|c|c|c|}
\hline \multirow{3}{*}{$\begin{array}{l}\text { Health behavior } \\
\text { related parts }\end{array}$} & \multicolumn{4}{|c|}{ Pre-intervention } & \multicolumn{4}{|c|}{ Post-intervention } & \multirow{3}{*}{$\begin{array}{c}\text { Chi } \\
\text { square } \\
\text { test }\end{array}$} & \multirow{3}{*}{$\begin{array}{c}\mathbf{P} \\
\text { value }\end{array}$} \\
\hline & \multicolumn{2}{|c|}{$\begin{array}{c}\text { Unsatisfactory } \\
<75 \%\end{array}$} & \multicolumn{2}{|c|}{$\begin{array}{c}\text { Satisfactory } \\
\geq 75 \%\end{array}$} & \multicolumn{2}{|c|}{$\begin{array}{c}\text { Un-satisfactory } \\
<75 \%\end{array}$} & \multicolumn{2}{|c|}{$\begin{array}{c}\text { Satisfactory } \\
\geq 75 \%\end{array}$} & & \\
\hline & No & $\%$ & No & $\%$ & No & $\%$ & No & $\%$ & & \\
\hline Avoid infection & 102 & 71.8 & 40 & 28.2 & 16 & 11.3 & 126 & 88.7 & 107.23 & $<0.001^{* * *}$ \\
\hline $\begin{array}{l}\text { Avoid urinary tract } \\
\text { infection }\end{array}$ & 107 & 75.4 & 35 & 24.6 & 19 & 13.4 & 123 & 86.6 & 110.47 & $<0.001^{* *}$ \\
\hline $\begin{array}{l}\text { Healthy nutrition for } \\
\text { hemodialysis }\end{array}$ & 105 & 73.9 & 37 & 26.1 & 23 & 16.2 & 119 & 83.8 & 95.63 & $<0.001 * *$ \\
\hline $\begin{array}{l}\text { Avoid renal failure } \\
\text { complication }\end{array}$ & 101 & 71.1 & 41 & 28.9 & 22 & 15.5 & 120 & 84.5 & 89.50 & $<0.001 * *$ \\
\hline $\begin{array}{l}\text { Avoid haemodialysis } \\
\text { complication }\end{array}$ & 106 & 74.6 & 36 & 25.4 & 21 & 14.8 & 121 & 85.2 & 102.90 & $<0.001^{* * *}$ \\
\hline Skin care & 107 & 75.4 & 35 & 24.6 & 19 & 13.4 & 123 & 86.6 & 110.47 & $<0.001^{* * *}$ \\
\hline Fistula care & 110 & 77.5 & 32 & 22.5 & 20 & 14.1 & 122 & 85.9 & 114.90 & $<0.001^{* * *}$ \\
\hline $\begin{array}{l}\text { Follow medication } \\
\text { regimen }\end{array}$ & 102 & 71.8 & 40 & 28.2 & 25 & 17.6 & 117 & 82.4 & 84.44 & $<0.001 * *$ \\
\hline $\begin{array}{l}\text { improving activity } \\
\text { and body condition }\end{array}$ & 111 & 78.2 & 31 & 21.8 & 20 & 14.1 & 122 & 85.9 & 117.33 & $<0.001 * *$ \\
\hline follow up care & 102 & 71.8 & 40 & 28.2 & 28 & 19.7 & 114 & 80.3 & 77.68 & $<0.001^{* * *}$ \\
\hline Avoid stress & 110 & 77.5 & 32 & 22.5 & 24 & 16.9 & 118 & 83.1 & 104.50 & $<0.001^{* *}$ \\
\hline $\begin{array}{l}\text { Marriage } \\
\text { relationship }\end{array}$ & 113 & 79.6 & 29 & 20.4 & 23 & 16.2 & 119 & 83.8 & 114.28 & $<0.001 * *$ \\
\hline $\begin{array}{l}\text { improving Social } \\
\text { relationship }\end{array}$ & 109 & 76.8 & 33 & 23.2 & 18 & 12.7 & 124 & 87.3 & 117.95 & $<0.001^{* *}$ \\
\hline $\begin{array}{l}\text { improving Spiritual } \\
\text { condition }\end{array}$ & 113 & 79.6 & 29 & 20.4 & 24 & 16.9 & 118 & 83.1 & 111.70 & $<0.001 * *$ \\
\hline $\begin{array}{l}\text { improving Emotional } \\
\text { condition }\end{array}$ & 111 & 78.2 & 31 & 21.8 & 18 & 12.7 & 124 & 87.3 & 122.84 & $<0.001 * *$ \\
\hline $\begin{array}{l}\text { Total health behavior } \\
\text { score }\end{array}$ & 104 & 73.2 & 38 & 26.8 & 20 & 14.1 & 122 & 85.9 & 101.00 & $<0.001 * *$ \\
\hline
\end{tabular}




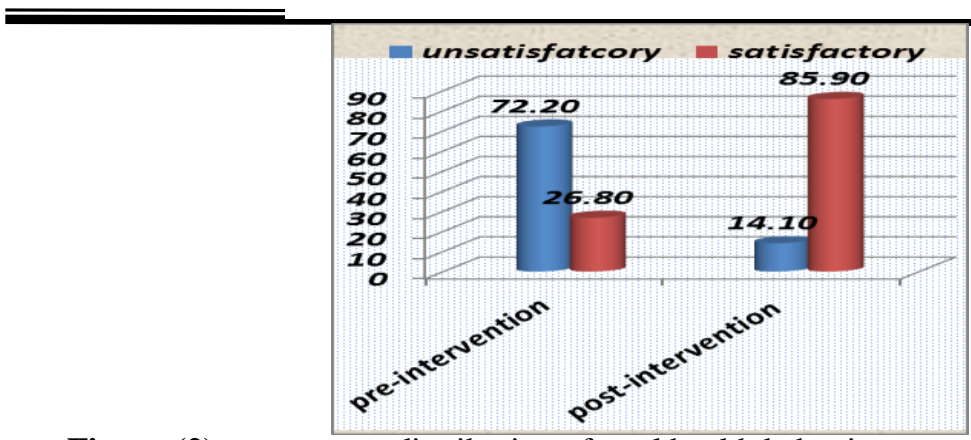

Figure (2): percentage distribution of total health behavior score of studied patients regarding renal failure pre and post intervention.

This figure reveled that, distribution of total score for healthy behaviors related main aspects among the studied patients pre and post intervention, it was showed that there was a highly statistical significant difference $(\mathrm{P}<0.001)$.

Table (4): Shows the distribution of total quality of life domains scores of the studied patients pre and post intervention, it was showed that there was highly statistical significant difference $(\mathrm{P}<0.001)$.

Table (4): Distribution of total quality of life domains scores of the studied patients pre and post intervention $(\mathrm{N}=142)$.

\begin{tabular}{|c|c|c|c|c|c|c|c|c|c|c|}
\hline \multirow{3}{*}{ Item } & \multicolumn{4}{|c|}{ Pre-intervention } & \multicolumn{4}{|c|}{ Post-intervention } & \multirow{3}{*}{$\begin{array}{c}\text { Chi } \\
\text { square } \\
\text { test }\end{array}$} & \multirow{3}{*}{$P$ value } \\
\hline & \multicolumn{2}{|c|}{$\begin{array}{c}\text { Unsatisfactory } \\
<\mathbf{6 0 \%}\end{array}$} & \multicolumn{2}{|c|}{$\begin{array}{c}\text { Satisfactory } \\
\geq \mathbf{6 0 \%} \\
\end{array}$} & \multicolumn{2}{|c|}{$\begin{array}{c}\text { Unsatisfactory } \\
<60 \% \\
\end{array}$} & \multicolumn{2}{|c|}{$\begin{array}{l}\text { Satisfactory } \\
\geq \mathbf{6 0 \%}\end{array}$} & & \\
\hline & No & $\%$ & No & $\%$ & No & $\%$ & No & $\%$ & & \\
\hline $\begin{array}{l}\text { Physical } \\
\text { condition }\end{array}$ & 107 & 75.4 & 35 & 24.6 & 14 & 9.9 & 128 & 90.1 & 124.54 & $<0.001 * *$ \\
\hline $\begin{array}{l}\text { Psychological } \\
\text { condition }\end{array}$ & 119 & 83.8 & 23 & 16.2 & 16 & 11.3 & 126 & 88.7 & 149.78 & $<0.001^{* *}$ \\
\hline Social condition & 116 & 81.7 & 26 & 18.3 & 19 & 13.4 & 123 & 86.6 & 109.09 & $<0.001^{* *}$ \\
\hline $\begin{array}{l}\text { Spiritual } \\
\text { condition }\end{array}$ & 111 & 78.2 & 31 & 21.8 & 19 & 13.4 & 123 & 86.6 & 120.69 & $<0.001 * *$ \\
\hline $\begin{array}{l}\text { Activity of } \\
\text { daily living }\end{array}$ & 104 & 73.2 & 38 & 26.8 & 15 & 10.6 & 127 & 89.4 & 114.56 & $<0.001 * *$ \\
\hline $\begin{array}{l}\text { Total quality of } \\
\text { life score }\end{array}$ & 111 & 78.2 & 31 & 21.8 & 18 & 12.7 & 124 & 87.3 & 122.48 & $<0.001^{* *}$ \\
\hline
\end{tabular}

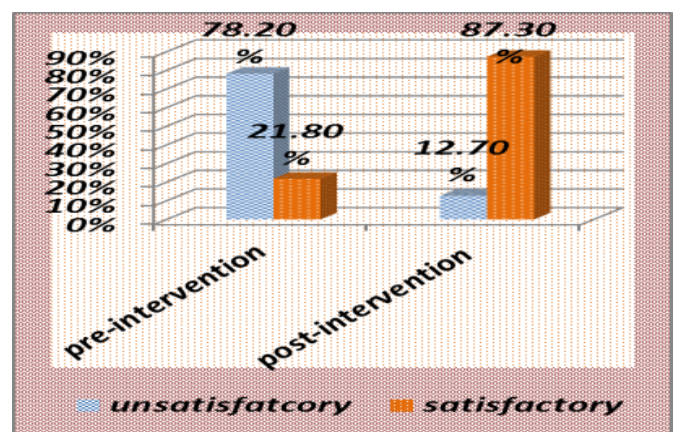

Figure (3): percentage distribution of total quality of life score of studied patients pre and post intervention. 
Mona Salah Mustafa, et. al.

This figure shows the distribution of total quality of life domains scores of the studied patients pre and post intervention, it was showed that there was highly statistical significant difference $(\mathrm{P}<0.001)$.

Table (5): The mean score of laboratory investigation values of the studied patients pre and post intervention $(\mathrm{N}=142)$.

\begin{tabular}{|c|c|c|c|c|}
\hline & Pre-intervention & Post-intervention & \multirow{2}{*}{$\begin{array}{c}\text { Paired } t \\
\text { test }\end{array}$} & \multirow[b]{2}{*}{$P$ value } \\
\hline & Mean \pm SD & Mean \pm SD & & \\
\hline Urea & $123.0493 \pm 65.26100$ & $79.1479 \pm 45.99722$ & 15.877 & $<0.001 * *$ \\
\hline Creatinine & $8.1401 \pm 3.78755$ & $4.1232 \pm 2.33881$ & 15.987 & $<0.001 * *$ \\
\hline Calcium & $9.0120 \pm 1.85658$ & $4.8549 \pm 2.05918$ & 25.351 & $<0.001 * *$ \\
\hline Phosphorus & $5.6246 \pm 1.91690$ & $2.8913 \pm 1.32205$ & 19.807 & $<0.001 * *$ \\
\hline Sodium & $165.0423 \pm 14.09133$ & $123.8331 \pm 31.59333$ & 13.176 & $<0.001 * *$ \\
\hline Potassium & $5.7838 \pm 1.06035$ & $3.3613 \pm 1.29049$ & 17.938 & $<0.001 * *$ \\
\hline
\end{tabular}

Table (5): Illustrates the mean score of laboratory investigation of the studied patient pre and post intervention, it was pointed out that that there was highly statistical significant difference $(\mathrm{P}<0.001)$.

Table (6): correlation between the studied patients total knowledge, quality of life, and healthy behaviors total score at the post intervention phase $(\mathrm{N}=142)$.

\begin{tabular}{|c|l|c|c|c|}
\hline \multicolumn{2}{|c|}{} & $\begin{array}{c}\text { Total } \\
\text { quality } \\
\text { score }\end{array}$ & $\begin{array}{c}\text { Total } \\
\text { behavior } \\
\text { score }\end{array}$ & $\begin{array}{c}\text { Total knowledge } \\
\text { score }\end{array}$ \\
\hline \multirow{2}{*}{$\begin{array}{c}\text { Total quality } \\
\text { score }\end{array}$} & Pearson Correlation & 1 & $.544^{* *}$ & 128 \\
\cline { 2 - 5 } $\begin{array}{c}\text { Total behavior } \\
\text { score }\end{array}$ & Sig. (2-tailed) & & .000 & .128 \\
\cline { 2 - 5 } $\begin{array}{c}\text { Total knowledge } \\
\text { score }\end{array}$ & Sig. (2-tailed) & .000 & 1 & .121 \\
\cline { 2 - 5 } & Pearson Correlation & .128 & .121 & .150 \\
\hline
\end{tabular}

Table (6): illustrates correlation between the studied patients total knowledge, quality of life, and healthy behaviors total score at the post intervention phase, it was revealed that there was a positive association $(\mathrm{P}<0.001)$.

\section{Discussion:}

The current study result revealed that demonstrate mean score of patient knowledge regarding general knowledge about renal failure pre and post intervention, it was indicated that there was a highly statistical significant difference between general renal failure knowledge mean score at the pre and post intervention phases of the program. This finding agreed with Kazley, Johnson, Simpson, Chavin, and Baliga (2014) ${ }^{[10]}$, who found that, Knowledge is fundamentally important to clinicians caring for patients with kidney diseases.

As regards patients' knowledge regarding care of renal failure pre and post intervention, it was indicated that there was a highly statistical significant difference between care of renal failure knowledge mean score at the pre and post intervention phases of the program. The present study result also indicated that 3quarters of patients had satisfactory data after health beliefs model based program. This is similar to Teera, luz, Songyot, Tangsa, Chaivat, Tritasavit, Inthria, and 


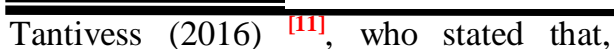
patients with hemodialysis due to their specific culture and environment, want special and steady education so as to adapt to physical and mental disabilities. Though adherence of special diet by patients is supplements to dialysis and is suggested for effectively mangment signs and symptoms of uremic syndrome associated with long term prevention of disease. This finding was parallel with Esmaili, Majlessi, Montazeri, Sadeghi, Nedjat, and Zeinali (2016) ${ }^{[12]}$, who expressed that, patients who received education had increased improvement of knowledge.

In the present study reported that, there was a highly statistically significant difference among the study group pre/post health beliefs model based program implementation regarding to health behavior. This finding may be resulting to the knowledge and skills patients acquired from the health beliefs model based program. The study result also indicated that two third of patients had satisfactory health behavior after health beliefs model based program. This is similar to Abo Deif, Elsawi, Selim, and Nasr Allah (2015) ${ }^{[13]}$, who stated that, to improve hemodialysis patient condition must be enhancing positive attitudes among patients and their perceptions of behavioral management. Therefore, it is necessary to provide hemodialysis patients with education to improve and modify their health awareness and attitude.

In the present study, there were statistically significant differences among the study group between before and after implementation of the health beliefs model based program in relation to QOL. This difference in QOL found among the studied group might be related to the health beliefs model based program application, patients after health beliefs model based program became more knowledgeable and had skills to avoid and manage complications and side effects.
This was supported by Joshi (2014) ${ }^{\text {[14], }}$ who stated that, the quality of life has a significant correlation with health locus of control beliefs. Therefore, it is necessary to provide hemodialysis patients with education to improve and modify their health awareness and attitude.

The present study indicated that laboratory investigation of the studied patient pre and post intervention, it was pointed out that there was highly statistical significant difference between studied patient laboratory investigation values at the pre and post intervention phases of the program. This finding was supported by Mohmoud et al (2015) ${ }^{[15]}$, revealed that the low QoL levels contribute to sociodemographic profile and medical-clinical and laboratory characteristics of hemodialysis patients. Similarly Guerrero et al (2012) ${ }^{[16]}$, reported that health education, dietary modifications, and medications tends to be enhance laboratory investigation. On the same line, Ahrari et al (2014) ${ }^{[17]}$, concluded that, lifestyle restrictions can impact on patients' illness beliefs, laboratory investigation, sense of perso nal control leading to anxiety and depression, inhibiting coping, and adjustment patients with a way of confidence in their ability to perform self-care behaviors are more probably to actual perform these tasks. so, people with high levels of self-care are ready to manage their end stage of renal disease (ESRD).

In this study revealed that there were highly positive statistically significant correlations between studied patient total knowledge, quality of life, and behavior total score at the post intervention phase. This finding clarified that when patients' level of knowledge and performance promoted, their self-care also promoted. Onoruoiza et al (2015) [3] reported that health Beliefs Model is important guides for understanding Noncompliance to disease information. 
Similarly, Clarke et al (2016) ${ }^{[18]}$, reported that their relationship between health information and quality of life. This is similar to Teera, et al, (2016) ${ }^{[11]}$, who stated that, patients with hemodialysis resulting to their culture and specific environment, need special and steady education in order to adapt to mental and physical abnormalities. though adherence of special diet by patients is supplements to hemodialysis and is importuned for effectively control symptoms and signs of uremic syndrome associated with longterm prevention of disease.

\section{Conclusion:}

The present study concludes that health belief Model (HBM) based program has statistically significant positive effect on health behavior, knowledge, quality of life, and laboratory investigation for patients undergoing haemodialysis. So the present study revealed that there were statistically significant positive correlations between studied patient total knowledge, quality of life, and health behavior total score at the post intervention phase.

\section{Recommendation:}

Based upon the findings of the study, the following recommendations are suggested:

- Application of health beliefs model program is important for the dialysis patient, they establishment of patients' educational centers in hospitals equipped by suitable related materials, medias and audio-visual aids for teaching all hemodialysis patients how to adhere to a prescribed regimen.

- Health beliefs model based program and counseling should begin predialysis to help patients undergoing hemodialysis identify existing coping strategies and to develop new ones.

\section{References:}

1. Vazini H, \& Barati M. (2014): The health belief model and self-care behaviors among type 2 diabetic patients. Iranian journal of diabetes and obesity. Volume (6). No (3). Pp 107111.

2. Grove D, Anne M, and Marks K. (2014): A guide to conservative kidney management information for health care professionals. 1st edition. Oxford university hospitals. Oxford. PP 32-35.

3. Onoruoiza S. I, Musa A, Umar B, and Kunle Y. S. (2015): Using health beliefs model as an intervention to noncompliance with hypertension information among hypertensive patient. IOSR journal of humanities. Volume (20). No (9). Pp 11-16. www.iosrjournals.org accessed at 22/1/2017.

4. Mollaoglu M. (2013): Quality of life in patients undergoing hemodialysis. Hiromichi Suzuki. Turkey. Chapter (37). Pp 105-110. www.dx.doi.org accessed at 24/5/2016.

5. Thomas $\mathbf{N}$ (2014): Renal nursing. 4th edition. John Wiley and sons. London. Pp 200-230

6. Friedman E, and Mallappallil $M$. (2016): Introduction and options in therapy in present and future therapies for end-stage renal disease. Volume (2). Pp -1-7.

7. WorldHealth Organization(WHO) (2012): prevalence of chronic renal failure. http://www.who.int accessed at $22 / 11 / 2016$

8. Lindberg M. (2010): Excessive fluid overload among haemodialysis patients: Prevalence, individual characteristics and self-regulation of fluid intake. theses and dissertations. Paper 551. Faculty of medicine. Uppsala University. P 68.

9. Farrokhi F. (2013): A patient opinion survey to identify perceived barriers to 
the introduction of a screening program for depression in ahaemodialysis population. Master thesis. Institute of Health Policy. Toronto University. P 91.

10. Kazley A, Johnson E, Simpson K, Chavin K, and Baliga P, (2014): health care provider perception of chronic kidney disease: knowledge and behavior among African American patients. Bmonephrol. www.biomedcentral.com accessed at 25/3/2017.

11. Teera Y, Luz A, Songyot P, Tangsa $S$, Chaivat $S$, Tritasavit $N$, Intheria Y, and Tantivess S, (2016): How to meet the demand for good quality renal dialysis as part of universal health coverage in resource-limited setting? Health-policy-system. www.biomedcentral.com accessed at 20/3/2017

12. Esmaili H, Majlessi F, Montazeri A, Sadeghi R, Nedjat S, and Zeinali J, (2016): dialysis adequacy and necessity of implement health education models to its promotion in Iran. International journal of medical research. Volume (5). No (10). Pp 116121. WWW.ijmrhs.com accessed at $9 / 4 / 2017$

13. Abo Deif $H$, Elsawi K, Selim M, and Nasr Allah M, (2015): effect of an educational program on adherence to therapeutic regimen among chronic kidney disease stage 5 (CKD5) patients under maintenance hemodialysis. Volume (6). No (5). Pp 21-31. Zzhhaa77@hotmail.com accessed at 8/4/2017
14. Joshi V.D, (2014): quality of life in end stage renal disease patient. World nephron journal. Volume (3). No (4). Pp 308-316.

15. Mahmoud S, and Abd Elaziz N.A, (2015): Association between health locus of control, self-care and selfefficacy in patients with end stage renal disease undergoing hemodialysis. Life science journal. Volume (12). No (11). Pp 58-72.

16. Guerrero V.G, Alvarado O.S, and Espina M.C, (2012): quality of life in people with chronic hemodialysis: association with sociodemographic medical-clinic and laboratory variables. Sci Elo analytics journal. Volume (20). No (5). Pp 30-35. www.scielo.br accessed at 22/3/2017

17. Ahrari S, Moshki M, and Bahrami M, (2014): the relationship between social support and adherence of dietary and fluids restriction among hemodialysis patients in Iran. Journal of caring sciences. Volume (3). No (1). Pp 11-19.

18. Clarke A. L, Yates T, Smith A, and Chilcot J, (2016): patients perceptions of chronic kidney disease and their association with psychosocial and clinical outcomes. Clin kidney journal. Volume (9). No (3). Pp 494-502 